\title{
The impact of urban wastewater discharges in quality of River Sitnica
}

\author{
Besime Kajtazi \\ European Union Office in Kosovo
}

\begin{abstract}
:
Wastewater treatment is a growing problem in Kosovo. Pollution from urban wastewaters poses the greatest pressure on Kosovo rivers and their better management represents an important area of improving their ecological status. Kosovo is lacking behind in terms of achieving certain goals and implementing European Environmental Directives, especially the Urban Wastewater Treatment Directive and the Industrial Emissions Directive. The lack of wastewater treatment plants prior to their discharge into receiving waters presents a gap in the water sector which needs to be addressed in order to meet European standards. According to the reports of water utilities companies, the level of sewerage services in the country is $65 \%$ while the level of wastewater treatment is $0.7 \%$. Kosovo, as a country with a European perspective, must approach this issue as soon as possible. The National Water Strategy aims at protecting water resources through treating wastewater before returning to the nature. According to this strategy, a number of wastewater treatment plants and accompanying infrastructure for main cities should be build.

River Sitnica is main river stretching in Kosovo valley, where main urban areas are located including capital Prishtina. The pollution of recipient Sitnica was monitored for a period of time at a point/profile, where already the wastewater from main urban areas are discharged. The monitoring was done by taking water samples on monthly basis and analysing the main parameters according to standard methods conducted in hydrometeorological institute. The results of the analysed parameters in river Sitnica, were confirming the pollution coming from sewage despite that river was doing some self-purification. Analysing the results of these parameters we notice a continuous increase from year to year. This is a consequence of rapid urbanization and increased wastewater discharges. Because of this continuous increase, the river is losing the self-purification power and its ecological statues is becoming critical.

With aim of protection the quality of river Sitnica, a study recommends construction of adequate infrastructure for collection of sewage and wastewater treatment plant for capital Prishtina and surrounding settlements before their discharge into the nature.
\end{abstract}

Keywords: urban wastewater; wastewater management; clean rivers; 